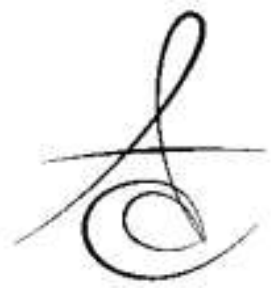

\title{
İSKELETSEL SINIF I MALOKLÜZYONA SAHİP HASTALARIN FARENGEAL HAVAYOLU BOYUTLARI VE HYOİD KEMİK POZİSYONUNUN CİNSİYETE GÖRE İNCELENMESİ
}

\section{ASSESSMENT OF PHARYNGEAL AIRWAY DIMENSIONS AND HYOID BONE POSITION OF PATIENTS WITH SKELETAL CLASS I MALOCCLUSION ACCORDING TO GENDER}

Dr. Öğr. Üy. Muhammed Hilmi BÜYüKÇAVUş*

Prof. Dr Hikmet ORHAN**

Uzm. Dt. Gönül KOCAKARA*

Makale Kodu/Article code: 4240

Makale Gönderilme tarihi; 04.12 .2019

Kabul Tarihi: 13.08.2020

DOI : $10.17567 /$ ataunidfd. 780079
M. Hilmi Büyükçavuş: ORCID ID: 0000-0003-2184-1549

Hikmet Orhan: ORCID ID: 0000-0002-8389-1069

Gönül Kocakara: ORCID ID: 0000-0001-6659-3548

ÖZ

Amaç: Bu çalışmanın amacı; iskeletsel Sınıf I malokluzyona sahip hastaların farengeal havayolu boyutları ve hyoid kemik pozisyonunu cinsiyetlere göre incelenmektir.

Gereç ve Yöntem: Çalışmamıza kliniğimize tedavi amacıyla başvurmuş, dâhil edilme kriterlerini taşıyan 67'si kadın ve 62'si erkek olmak üzere toplam 129 birey dâhil edilmiştir. Çalışmaya dâhil edilen bireyler; cinsiyetlere göre gruplandırılarak, sefalometrik filmler üzerinde farengeal havayolu ölçümleri ve hyoid ölçümleri karşılaştırılarak incelenmiştir. Araştırmamızda 21 farengeal havayolu ölçümü, 11 hyoid kemik ölçümü kullanılmıștır. Cinsiyete göre gruplamada bağımsız grup t-testi kullanılmıştır. Elde edilen bulgular SPSS 20.0 programı kullanılarak değerlendirilmiştir.

Bulgular: Çalışmamızdan elde ettiğimiz bulgulara göre; kadın grubundaki 67 hastanın kronolojik yaşlarının ortalaması 13,29 \pm 2,83 yıl, erkek grubundaki 62 hastanın kronolojik yaşlarının ortalaması 13,62 $\pm 2,61$ yıl olarak bulunmuştur. Çalışmada cinsiyet grupları ile kronolojik yas ve büyüme-gelişim dönemleri arasında istatistiksel olarak anlamlı ilişki gözlenmemiștir ( $p>0.05)$. Kadın ve erkek grupları arasında nazofarenks kısmında yer alan ölçümlerden AD1-Ba(mm), AD2-Ho(mm), PNS-Ho(mm) ölçümlerinde istatistiksel olarak anlamlı fark bulunmuștur $(p<0.05)$. Üst posterior havayolu uzunluğunda (ÜPHU) ve epiglottik havayolu uzunluğunda (EHU) da iki grup arasında istatistiksel olarak anlamlı bir fark tespit edilmiştir $(p<0.05)$. Hyoid kemiğin pozisyonunu değerlendirdiğimiz ölçümlerden $\mathrm{Hy}-\mathrm{A}(\mathrm{mm})$ ölçümü ve hyoid kemiğin mandibular düzleme olan uzaklı̆ı Hy - $\mathrm{MD}(\mathrm{mm})$ ölçümü dışındaki hyoid ölçümlerinin tamamında kadınlar ve erkekler arasında istatistiksel olarak anlamlı bir fark bulunmuştur $(p<0.05)$. Sonuç: Erkeklerde havayolu boyutlarının ve alan ölçümlerinin genel olarak daha fazla olduğu görülmüştür. Hyoid kemik pozisyonunda ise, erkeklerde hyoid kemiğin vertikal olarak aşağıda ve önde olduğu sonucuna ulaşılmıştır.

Anahtar Kelimeler: Farengeal havayolu, Hyoid kemik, Sefalometri

\section{ABSTRACT}

Aim: The aim of this study; to evaluate pharyngeal airway dimensions and hyoid bone position according to gender in patients with skeletal Class I Malocclusion.

Material - Methods: A total of 129 individuals(67 females and 62 males) who met the inclusion criteria were included in the study. Individuals included in the study were grouped according to gender and pharyngeal airway measurements and hyoid measurements were compared on cephalometric films. In our study, 21 pharyngeal airway measurements and 11 hyoid measurements were used. Independent group t-test was used to group by gender. The findings were evaluated using SPSS 20.0 program.

Results: According to the findings of our study; mean age of the 67 patients in the female group was $13.29 \pm 2.83$ years, while the mean age of the 62 patients in the male group was $13.62 \pm 2.61$ years. No statistically significant relationship was observed between sex groups and chronological age and growth-development periods $(p>0.05)$. There was a statistically significant difference between female and male groups in the measurements of $A D 1-B a(m m), A D 2-H o(m m), P N S-H o(m m)$ of the nasopharynx $(p<0.05)$. A statistically significant difference was found between the two groups in the upper posterior airway length(UPHU) and epiglottic airway length $(\mathrm{EHU})(\mathrm{p}<0.05)$. There was a statistically significant difference between male and female in all hyoid measurements except the $\mathrm{Hy}-\mathrm{A}(\mathrm{mm})$ and $\mathrm{Hy}-\mathrm{MD}(\mathrm{mm})$ measurements in which we evaluated the position of the hyoid bone $(p<0.05)$

Conclusion: Pharyngeal airway size and area measurements were found to be higher in males. In the hyoid bone position, it was concluded that the hyoid bone was vertically below and anterior in males.

Keywords: Pharyngeal airway, Hyoid bone, Cephalometry

\footnotetext{
Isparta Süleyman Demirel Üniversitesi Diş Hekimliği Fakültesi Ortodonti AD, Isparta, Türkiye

** Isparta Süleyman Demirel Üniversitesi Tıp Fakültesi, Biyoistatistik ve Tıbbi Bilișim Anabilim Dalı, Isparta, Türkiye

Kaynakça Bilgisi Büyükçavuş MH, Orhan H, Kocakara G. İskeletsel sınıf I maloklüzyona sahip hastaların farengeal havayolu boyutları ve hyoid kemik pozisyonunun cinsiyete göre incelenmesi. Atatürk Üniv Diş Hek Fak Derg 2020; 30: 599-606.

Citation Information: Buyukcavus MH, Orhan H, Kocakara G. Assessment of pharyngeal airway dimensions and hyoid bone position of patients with skeletal class I malocclusion according to gender. J Dent Fac Atatürk Uni 2020; 30: 599-606.
} 


\section{GİRİş}

Havayolu, üst havayolu (farengeal havayolu) ve alt havayolu olmak üzere iki kısma ayrılır. Farengeal havayolu; solunum sisteminin nostriller, dudaklar ve trakea arasında kalan bölümüdür. Solunum yolunun inferiordaki kısmı ise alt havayolu olarak adlandırılır. Larenksin vokal kordlarından başlayarak bronşiyollere kadar uzanır. ${ }^{1}$

Farengeal havayolu; havayı Isıtma ve nemlendirme, koku alma yollarını oluşturma, yemeklerin aspirasyonunu önleme, yutkunma sırasında ventilasyonu sağlama, konuşma ve enfeksiyonlara karşı primer koruma gibi kraniyofasiyal fonksiyonlarda rol alır. ${ }^{2}$ Bütün bu fonksiyonlar istemli ve istemsiz nöromuskuler sistem tarafından kontrol edilmektedir. ${ }^{2,3}$

Farengeal havayolunun büyük bir kısmının kraniyofasiyal kompleks içinde yer alması sebebiyle, ortodontistler teşhis ve planlama için havayolunu da incelemekte ve oluşmuş ya da oluşabilecek tıkanıklık durumunda havayolunu düzenleyebilmektedirler. Bu da ortodonti uzmanlarını, farengeal havayolunda komp likasyonlar oluştuğunda veya gelişebileceği zaman müdahale etmek için önemli bir yere taşımaktadır.

Hyoid kemik ile kraniyofasiyal yapılar arasındaki ilişki de uzun yıllardan beri dikkat çeken bir konu olmuştur. Hyoid kemik; solunumun devam edebilmesi, kraniyal dengenin sağlanması ve dilin desteklenmesi gibi görevlere sahiptir. Hyoid kemiğin pozisyonu ortodontik malformasyonlara, fasiyal yapıdaki bozukluklara, ağız solunumu alışkanlığına, yutkunma problemlerine bağlı olarak değişebilmektedir. Ayrıca ortodontik tedavinin prognozunun ve tedavi sonrası relapsının değerlendirilmesinde diagnostik öneme sahiptir. ${ }^{4-8}$

Farengeal havayolu boyutları da hyoid kemik pozisyonu da baş postürü, yaş, cinsiyet, maloklüzyon tipi, vertikal büyüme paterni, vücut kitle indeksi, gelişim dönemi, solunum şekli gibi birçok faktörden etkilenebilmektedir. ${ }^{9}$

Farengeal havayolu boyutları da hyoid kemik pozisyonu da erkek ve kadınlarda fark göstermektedir. ${ }^{10}$ Sağlıkı bireylerde farengeal yapıların, yumuşak damak ve dil uzunluğunun erkeklerde daha fazla olduğu rapor edilmiştir. ${ }^{11}$ Literatürde yapılan çalışmaların bazılarında cinsiyetler arasında farklılık bulunmazken, ${ }^{4,5,12}$ bazılarında da anlamlı düzeyde farklılık tespit

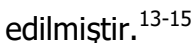

Farengeal havayolu boyutları ve hyoid kemik pozisyonunu değerlendirmek için literatürde farklı yöntemler kullanılmıştır. Rinometre, rinomanometre, rinoskopi, pnömatografi, pletismografi ve S.N.O.R.T gibi klinik yöntemlerin yanında frontal sefalometrik radyografiler, MRG (Magnetik Rezonans Görüntüleme), BT (Bilgisayarlı Tomografi), KIBT (Konik Işınlı Bilgisayarlı Tomografi) ve lateral sefalometrik radyografiler gibi radyolojik yöntemler de kullanılmaktadır. Çalışmalarda güncel olarak KIBT kullanımı popüler olsa da KIBT'nin radyasyon dozu, yüksek maliyet, rutin kullanıma uygun olmaması vb. nedenlerle literatürde en fazla lateral sefalometrik radyografilerde incelemeler yapılmıştır.

Çalışmamızın da amacı; iskeletsel Sınıf I malokluzyona sahip hastaların farengeal havayolu boyutları ve hyoid kemik pozisyonunu cinsiyetlere göre sefalometrik olarak incelemektir.

\section{GEREÇ VE YÖNTEM}

$\mathrm{Bu}$ retrospektif klinik çalışma, Süleyman Demirel Üniversitesi Diş Hekimliği Fakültesi Ortodonti Anabilim Dalı́na tedavi amacıyla başvuran hastalar ile gerçekleştirilmiştir. Çalışmamız için Süleyman Demirel Üniversitesi Tıp Fakültesi Klinik Araştırmalar Etik Kurulu'ndan (16.01.2019/7) etik kurul onayı alınmıştır. Çalışma Helsinki Deklarasyonu Prensipleri 'ne uygun olarak yapılmıştır. Kliniğimize tedavi amacıyla başvuran her hastadan 'Bilgilendirilmiş Olur Formu' ve materyallerinin bilimsel çalışma ve yayınlarda kullanılabileceğine dair form alınmaktadır. Çalışma için gerekli örnek büyüklüğü $0.05^{\prime}$ lik önem düzeyinde ve $\% 80$ güçte olacak şekilde G*Power analizi (G*Power Ver.3.0.10, Kiel, Germany) ile hesaplanmış ve her bir grup için minimum 21 bireyin gerekli olduğu tespit edilmiştir. Çalışmanın gücünü artırmak için ve olabilecek kayıplar da düşünülerek çalışmamıza daha fazla birey dâhil edilmiştir.

Hasta seçim kriterleri;

1. İskeletsel Sınıf I malokluzyona sahip olması $(0<A N B<4)$

2. Havayolunda herhangi bir patolojisi olmaması

3. Konjenital ve/veya edinilmiş herhangi bir anomalinin olmaması (dudak damak yarıkları vb.)

4. Daha önce ortodontik tedavi görmemiş olması

5. Başlangıç radyografilerinde referans noktalarının düzgün şekilde saptanabilmesi ve yeterli görüntü kalitesine sahip olması

6. Lateral sefalometrik film alınması esnasında baş pozisyonun doğru şekilde konumlandırılmış olmasıdır

Yukarıda belirtilen kriterlere göre incelenen 158 hastadan dâhil edilme kriterlerini taşıyan 67'si kadın ve 62'si erkek olmak üzere toplam 129 birey dâhil edilmiştir (Tablo 1). Çalışmaya dâhil edilen bireyler 
cinsiyete göre gruplandırılarak, gruplar arasında farengeal havayolu ölçümleri ve hyoid ölçümleri karşılaştırılarak incelenmiştir.

Tablo 1. Cinsiyet gruplarına göre demografik istatistikler

\begin{tabular}{|c|c|c|c|c|c|}
\hline & \multirow{2}{*}{$\begin{array}{c}\text { Kadın } \\
(n=67)\end{array}$} & & & \\
\hline & & & $\begin{array}{c}\text { Erkek } \\
(n=62)\end{array}$ & TOPLAM & $\mathbf{P}$ \\
\hline \multicolumn{2}{|l|}{$\begin{array}{c}\text { Yaş } \\
(\overline{\mathbf{x}} \pm \mathbf{S S})\end{array}$} & $\begin{array}{c}13,29 \pm \\
2,83\end{array}$ & $\begin{array}{c}13,62 \pm \\
2,61 \\
\end{array}$ & $\begin{array}{c}13,45 \pm \\
2,85 \\
\end{array}$ & $0,054 t$ \\
\hline \multirow{3}{*}{$\begin{array}{l}\text { Büyüme Gelişim } \\
\text { Dönemi } \\
\text { n (\%) }\end{array}$} & $\begin{array}{l}\text { Pre- } \\
\text { Peak }\end{array}$ & $21(31,34)$ & $20(32,25)$ & $41(100)$ & \multirow{3}{*}{$0,921^{*}$} \\
\hline & Peak & $20(29,85)$ & $20(32,25)$ & $40(100)$ & \\
\hline & $\begin{array}{l}\text { Post- } \\
\text { Peak }\end{array}$ & $26(38,8)$ & $22(35,48)$ & $48(100)$ & \\
\hline
\end{tabular}

†: Bağımsız grup t testi; *: Pearson ki-kare testi.

Çalışmamıza dâhil edilen hastaların tedavi başında fakültemiz Ağız Diş ve Çene Radyolojisi Anabilim Dalı'nda bulunan röntgen cihazı (Planmeca Promax, Helsinki, Finlandiya) ile elde edilmiş olan lateral sefalometrik filmleri kullanılmıştır. İncelenen lateral sefalometrik filmlerden, görüntü kalitesini etkileyecek problemi olmayanlar (magnifikasyon, düşük kontrast ve bulanıklık gibi) ve doğal baş pozisyonu ve/veya doğal baş pozisyonuna yakın şekilde alınmış olanlar seçilmiştir. Çalışmaya dâhil edilen lateral sefalometrik filmler Planmeca Romexis (Planmeca Romexis Viewer@, Helsinki,Finlandiya) yazılım programı üzerinde kalibrasyonları yapılarak 1:1 ölçüde gerçek boyutlarında aydınger kağıdı üzerine basılmıştır. Ardından 0,3 mm uçlu kurşun kalem yardımı ile aşağıda belirtilen sefalometrik nokta ve düzlemler çizilerek ölçümler yapılmıştır (Şekil 1). Alan ölçümleri ise dijital lateral sefalometrik filmler üzerinde SketchAndCalc ${ }^{\mathrm{TM}}$ yazılım programında (SketchAndCalc Area Calculator software, Axiom Welldone (c), https://www.sketchandcalc.com/) dijital kalibrasyon yapıldıktan sonra gerçekleştirilmiştir.

Lateral sefalometrik radyografiler üzerindeki farengeal havayolu ve hyoid kemik ölçümleri literatürde kullanılan yöntemlere bağlı kalınarak yapılmıştır. ${ }^{11}$ Araştırmamızda 21 tanesi farengeal havayolu ölçümü, 11 tanesi hyoid ölçümü kullanılmıştır. Değerlendirmede kullanılan ölçümler aşağıdaki gibidir (Şekil 1):

\section{Çalışmamızda Kullanılan Farengeal Havayolu Ölçümleri}

1. PNS-Ep: Vertikal havayolu uzunluğu; PNS ve Ep arasındaki mesafedir.

2. AD1-PNS: PNS'den bazyona çizilen doğrunun nazofarengeal duvarın posteriorunu kestiği AD1 noktası ile PNS arasındaki mesafedir.

3. AD1-Ba: PNS-Ba çizgisi boyunca Ba ile $A D 1$ arasındaki mesafedir.

4. AD2-PNS: S-Ba düzlemine PNS noktasından indirilen dikmenin düzlemine nazofarengeal duvarın posteriorunu kestiği AD2 noktası ile PNS arasındaki mesafedir.

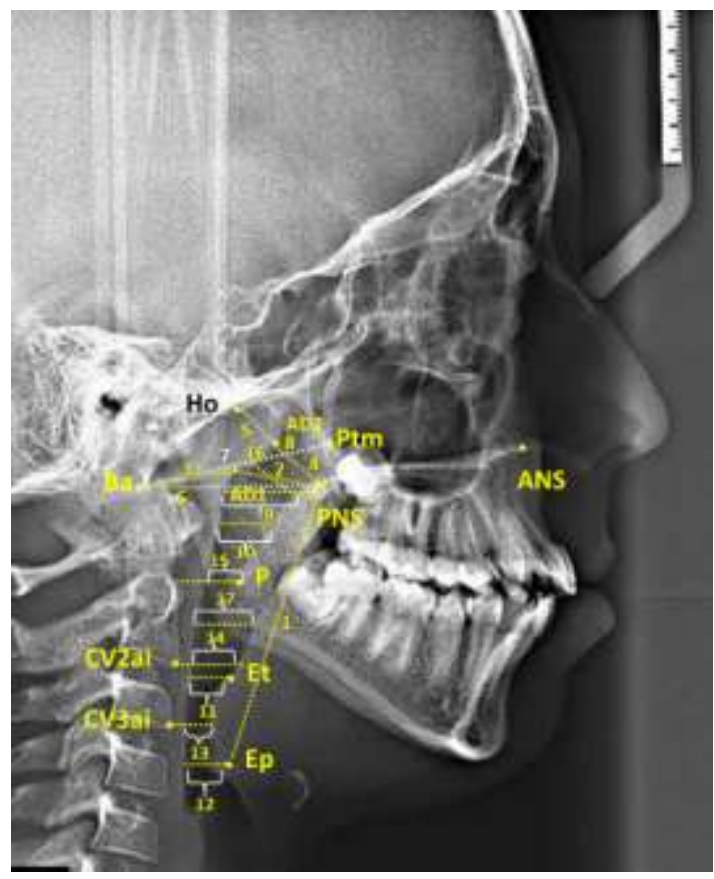

Şekil 1. Çalışmamızda kullanılan havayolu ölçümleri

5. AD2-Ho: AD2 noktası ile Ho noktası arasındaki mesafedir.

6. PNS-Ba: PNS noktası ile Ba noktası arsındaki mesafedir.

7. Ptm-Ba: Ptm noktası ile Ba noktası arasındaki mesafedir.

8. PNS-Ho: PNS noktası ve Ho noktası arasındaki mesafedir.

9. PFU (Palatal Farengeal Uzunluk - PNS-PPW1 (PPS)): Üst farengeal boşluk olarak da adlandırılır. PNS'den palatal düzleme paralel çizilen doğrunun nazofarengeal duvarda kestiği nokta ile arasındaki mesafedir.

10. ÜPFU (Üst Posterior Farengeal Uzunluk (SPPS)): Yumuşak damağın ortasından palatal düzleme paralel çizilen doğrunun posterior farengeal duvarda kestiği nokta ile arasındaki mesafedir.

11. EFU (Epiglottik Farengeal Uzunluk (EPS)): Epiglottisin en uç noktasından (Et) palatal düzleme paralel çizilen doğrunun posterior farengeal duvarda kestiği nokta ile arasındaki mesafedir.

12. HU (Hipofarengeal Uzunluk - Eb-PPW3): Epiglottisin en alt noktasından (Ep) palatal düzleme paralel çizilen doğrunun posterior farengeal duvarda kestiği nokta ile arasındaki 
mesafedir.

13. AHU (Alt Havayolu Uzunluğu): CV3ai ve CV3pi noktaların geçen doğrunun ön ve arka farenks duvarını kestiği noktalar arasındaki mesafedir.

14. AFU (Alt Farengeal Uzunluk (IPS)): CV2ai noktasından geçen, palatal düzleme paralel çizilen doğrunun ön ve arka farengeal duvarlarda kestiği noktalar arasındaki mesafedir.

15. OHU (Orta Farengeal Uzunluk - P-PPW2 (MPS)): $\mathrm{P}$ noktasından palatal düzleme paralel çizilen doğrunun posterior farengeal duvarda kestiği nokta ile arasındaki mesafedir.

16. Üst Havayolu (McNamara'nın üst farengeal uzunluğu): Yumuşak damaktan arka farengeal duvara olan en yakın mesafedir.

17. Alt Havayolu (McNamara'nın alt farengeal uzunluğu): Dilin arka kenarı ile mandibulanın kesiştiği noktadan posterior farengeal duvara olan minimum mesafedir.

18. Nazofarenks Alanı: ANS-PNS'den arka farenks duvarına olan doğru ve AD2 ile PNS'yi birbirine bağlayan doğru arasında kalan kesit alanıdır.

19. Orofarenks Alanı: ANS-PNS doğrusu, yumuşak damağın arka yüzeyi, dilin postero-inferior yüzeyi ve Et noktasında palatal düzleme paralel bir doğru ile belirtilen alandır.

20. Hipofarenks Alanı: Orofarenksin altında kalan ve alt sınırı Cv4ia'dan palatal düzleme paralel çizilen doğru olan, farengeal alandır.

21. Toplam Alan: Tüm üst farengeal havayolu alanıdır. Arka sınırı posterior farengeal duvar, ön sınırı anterior farengeal duvar, alt sınırı CV4 nolu vertebranın en alt ve en ön hizasından geçen ve palatal düzleme paralel olan doğrudur. Üst sınırı ise PNS-Ho düzlemidir.

\section{Çalışmamızda Kullanılan Hyoid Kemik Ölçümleri (Şekil 2)}

1. Hy-CV3ai: Hyoid kemiğin en ön ve üst noktası ile üçüncü servikal vertebranın en ön ve alt noktası arasındaki uzaklıktır.

2. Hy-A: A noktası ve Hy noktaları arasındaki uzaklıktır.

3. Hy-Pg: Pg noktası ve Hy noktaları arasındaki uzaklıktır.

4. Hy-S: $\mathrm{S}$ noktası ve Hy noktaları arasındaki uzaklıktır.

5. Hy-MD: Hyoid noktası ile mandibular düzlem arasındaki dik uzaklıktır.

6. Hy-SN: Hyoid noktası ile SN düzlemi arasındaki dik uzaklıktır.

7. Hy-FH: Hyoid noktası ile FH düzlemi arasındaki dik uzaklıktır.

8. Hy-PTV: Hyoid noktası ile PTV düzlemi arasındaki dik uzaklıktır.

9. Hy-N: N ve Hy noktaları arasındaki uzaklıktır.

10. Hy-VRD: Hyoid noktası ile VRD düzlemi arasındaki dik uzaklıktır.

11. Hy-HRD: Hyoid noktası ile HRD düzlemi arasındaki dik uzaklıktır.

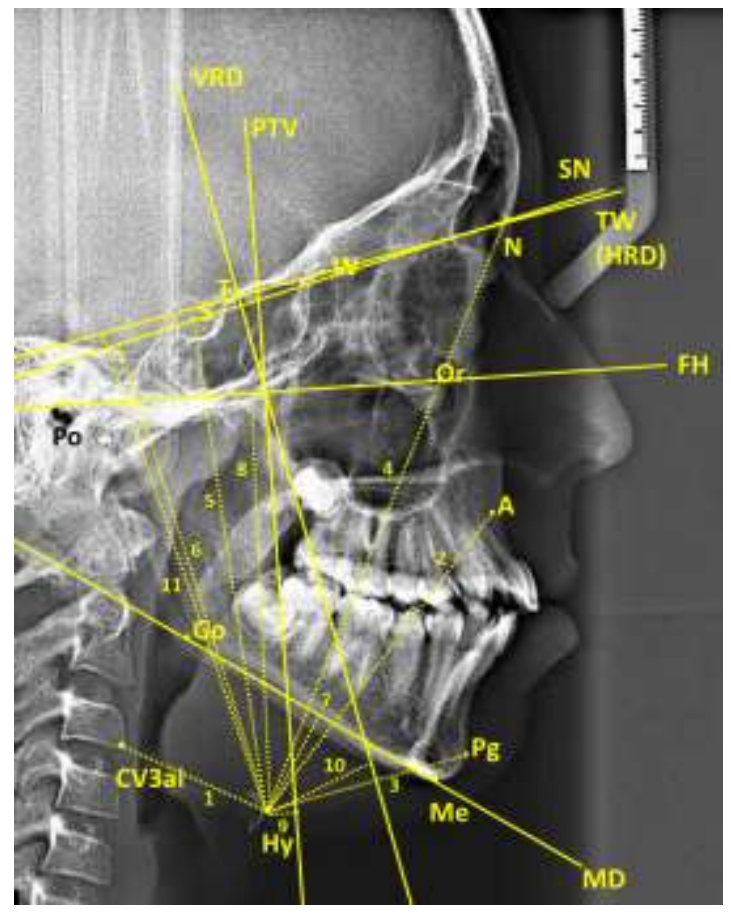

Şekil 2. Çalışmamızda kullanılan hyoid kemik ölçümleri

\section{İstatistiksel Analiz}

Verilerin normal dağılıma sahip olup olmadığı Kolmogorov-Smirnov testi ile belirlenmiştir. Çalışmada değerlendirilen parametrelerin normal dağıldığı tespit edildiğinden parametrik testler kullanılmıştır. Tanımlayıcı istatistikler $\bar{X}$ (Ortalama) \pm SS (Standart Sapma) şeklinde gösterilmiştir. Hastaların büyümegelişim (CVM-Servikal Vertebral Maturasyon) evrelerinin dağılımı Pearson ki-kare bağımsızlık testi ile karşılaştırılmıştır.

Cinsiyete göre hastaların kronolojik yaşları ve sefalometrik filmler üzerinde yapılan farengeal havayolu ve hyoid ölçümlerine ait ortalama farklarını değerlendirmede bağımsız grup t testi kullanılmıştır.

Yapılan ölçümlerin hata payını belirlemek için 129 lateral sefalometrik filmden rastgele seçilen 45 filmde ilk ölçümlerin yapılmasının ardından iki hafta sonra aynı araştırmacı tarafından ölçümler körleme

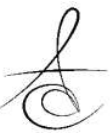


yapılarak tekrarlanmıştır. Her bir ölçüm için Cronbach a katsayıları belirlenmiştir. Ölçümlerimizdeki tekrarlanabilirlik katsayılarının yüksek olduğu tespit edilmiştir ( $a>0,80)$.

Verilerin analizinde SPSS paket programı (SPSS for Win, ver 20.0; SPSS Inc, Chicago, IIl) kullanılmıştır. Sonuçlar, $p<0.05$ anlamlılık düzeyinde istatistiksel olarak anlamlı kabul edilmiştir.

\section{Bulgular}

\section{- Demografik veriler}

Cinsiyete göre gruplanan hastaların kronolojik yaş ve büyüme-gelişim dönemine göre dağılımı Tablo 1'de gösterilmektedir. Kadın grubundaki 67 hastanın kronolojik yaşlarının ortalaması 13,29 \pm 2,83 yıl, erkek grubundaki 62 hastanın kronolojik yaşlarının ortalaması 13,62 \pm 2,61 yıl olarak bulunmuştur.

Gruplardaki bireylerin büyüme-gelişim dönemlerine bakıldığında ise, kadın grubunda 21 pre-peak, 20 peak ve 26 post-peak döneminde birey yer alırken, erkek grubunda 20 pre-peak, 20 peak ve 22 post-peak döneminde birey yer almıştır. Çalışmada cinsiyet grupları ile kronolojik yaş ve büyüme-gelişim dönemleri arasında istatistiksel olarak anlamlı ilişki gözlenmemiştir ( $p>0.05)$ (Grafik 1).

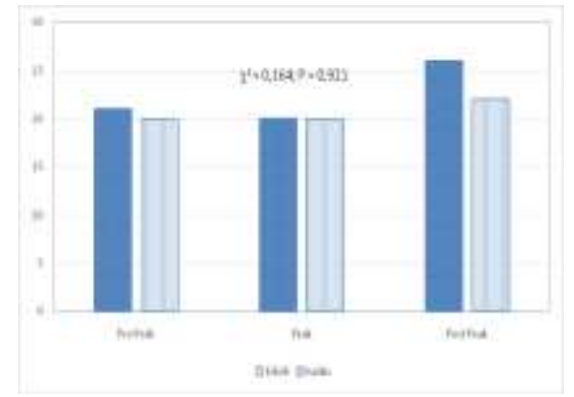

Grafik 1. Büyüme Gelişim Dönemlerinin Cinsiyetlere Göre Dağılımı

\section{- Farengeal havayolu bulguları}

Cinsiyet gruplarının havayolu üzerine etkilerini incelediğimizde; kadın ve erkek grupları arasında nazofarenks kısmında yer alan ölçümlerden $A D 1-B a(m m)$, $\mathrm{AD2}-\mathrm{Ho}(\mathrm{mm}), \mathrm{PNS}-\mathrm{Ho}(\mathrm{mm})$ ölçümlerinde istatistiksel olarak anlamlı fark bulunmuştur $(p<0.05)$. PNS$\mathrm{Ba}(\mathrm{mm}), \mathrm{Ptm}-\mathrm{Ba}(\mathrm{mm}), \mathrm{AD} 1-\mathrm{PNS}(\mathrm{mm}), \mathrm{AD} 2-\mathrm{PNS}(\mathrm{mm})$ ve posterior farengeal uzunluk (PFU) ölçümlerinde ve McNamara tarafından tanımlanan üst havayolu ölçümünde ise kadın ve erkekler arasında istatistiksel olarak anlamlı fark bulunmamıştır ( $p>0.05$ ) (Tablo 2).

Havayolu ölçümlerinin orofarenks kısmında yer alan vertikal havayolu uzunluğunda PNS-Ep(mm), orta havayolu uzunluğunda (OHU), alt farengeal uzunlukta (AFU) ve McNamara tarafından tanımlanan alt havayolu ölçümünde kadın ve erkekler arasında istatistiksel olarak anlamlı bir fark bulunmamıştır ( $p>0.05$ ). Üst posterior havayolu uzunluğunda (ÜPHU) ve epiglottik havayolu uzunluğunda (EHU) ise iki grup arasında istatistiksel olarak anlamlı bir fark tespit edilmiştir $\quad(p<0.05)$. Hipofarenks bölümündeki ölçümlerden hipofarengeal uzunlukta $(H U)$ ve alt havayolu uzunluğu (AHU) ölçümünde de kadın ve erkekler arasında istatistiksel olarak anlamlı fark bulunmamıştır ( $p>0.05$ ) (Tablo 2 ).

Tablo 2. Cinsiyete göre farengeal havayolu ölçümlerinin karşılaştırılması

\begin{tabular}{|c|c|c|c|c|}
\hline & Kadın & Erkek & \multirow{2}{*}{$\mathbf{P}$} \\
\hline & & $\overline{\mathbf{x}} \pm \mathbf{S S}$ & $\overline{\mathbf{x}} \pm \mathbf{S S}$ & \\
\hline \multirow{21}{*}{ 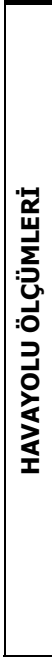 } & PNS-Ep & $56,45 \pm 8,19$ & $55,18 \pm 6,71$ & 0,051 \\
\hline & AD1-PNS & $22,32 \pm 4,85$ & $22,67 \pm 5,36$ & 0,429 \\
\hline & AD1-Ba & $21,21 \pm 4,67$ & $20,14 \pm 4,15$ & 0,005 \\
\hline & \begin{tabular}{|l|} 
AD2-PNS \\
\end{tabular} & $17,74 \pm 4,29$ & $17,95 \pm 4,34$ & 0,588 \\
\hline & \begin{tabular}{|l|} 
AD2-Ho \\
\end{tabular} & $12,06 \pm 3,96$ & $10,85 \pm 4,19$ & 0,001 \\
\hline & PNS-Ba & $43,29 \pm 5,20$ & $42,77 \pm 5,28$ & 0,253 \\
\hline & Ptm-Ba & $38,74 \pm 4,66$ & $38,55 \pm 3,92$ & 0,612 \\
\hline & PNS-Ho & $29,86 \pm 4,61$ & $29,09 \pm 3,62$ & 0,031 \\
\hline & PFU & $23,18 \pm 5,16$ & $24,20 \pm 5,48$ & 0,028 \\
\hline & ÜPHU & $9,56 \pm 2,82$ & $9,97 \pm 2,91$ & 0,098 \\
\hline & EHU & $10,38 \pm 3,16$ & $10,94 \pm 3,15$ & 0,042 \\
\hline & HU & $13,36 \pm 3,89$ & $13,91 \pm 3,37$ & 0,082 \\
\hline & AHU & $9,87 \pm 3,20$ & $10,33 \pm 3,35$ & 0,104 \\
\hline & AFU & $11,64 \pm 4,14$ & $13,19 \pm 4,27$ & 0,000 \\
\hline & OHU & $11,91 \pm 3,58$ & $12,48 \pm 3,58$ & 0,071 \\
\hline & Üst Havayolu & $6,97 \pm 2,42$ & $7,27 \pm 2,56$ & 0,175 \\
\hline & Alt Havayolu & $9,82 \pm 2,98$ & $10,33 \pm 3,11$ & 0,058 \\
\hline & Orofarenks Alanı & $449,99 \pm 133,20$ & $455,62 \pm 138,92$ & 0,635 \\
\hline & Nazofarenks Alani & $109,96 \pm 54,46$ & $117,97 \pm 63,45$ & 0,124 \\
\hline & Hipofarenks Alanı & $184,24 \pm 76,63$ & $224,02 \pm 89,88$ & 0,000 \\
\hline & Toplam Alan & $749,867 \pm 200,530$ & $792,00 \pm 217,99$ & 0,022 \\
\hline
\end{tabular}

Son olarak alan ölçümleri incelendiğinde, havayolunu oluşturan yapılardan nazofarenks alanı ve orofarenks alanı dışındaki hipofarenks alanı ve toplam alan ölçümlerinde kadın ve erkekler arasında istatistiksel olarak anlamlı bir fark bulunmuştur $(p<0.05)$. Nazofarenks ve orofarenks alanı ölçümlerinde ise erkeklerde kadınlara göre fazla ölçülmüş olsa da iki grup arasında istatistiksel olarak anlamlı fark bulunmamıştır ( $\mathrm{p}>0.05$ ) (Tablo 2).

\section{- Hyoid kemik bulguları}

Hyoid kemiğin pozisyonunu değerlendirdiğimiz ölçümlerden $H y-A(m m)$ ölçümü ve hyoid kemiğin mandibular düzleme olan uzaklığı Hy - $\mathrm{MD}(\mathrm{mm})$ ölçümü dışındaki hyoid ölçümlerinin tamamında kadınlar ve erkekler arasında istatistiksel olarak anlamlı bir fark bulunmuştur $(\mathrm{p}<0.05)$ (Tablo 3$)$. 
Tablo 3. Cinsiyete göre hyoid kemik ölçümlerinin karşılaştırıması

\begin{tabular}{|c|c|c|c|c|}
\hline & Kadın & Erkek & \\
\hline & & $\overline{\mathbf{x}} \pm \mathbf{S S}$ & $\overline{\mathbf{x}} \pm \mathbf{S S}$ & \\
\hline \multirow{11}{*}{ 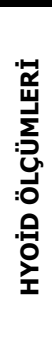 } & Hy - CV3ai & $30,65 \pm 4,45$ & $31,55 \pm 4,95$ & 0,029 \\
\hline & Hy - A & $69,55 \pm 8,08$ & $68,90 \pm 8,03$ & 0,358 \\
\hline & $\mathrm{Hy}-\mathrm{Pg}$ & $46,26 \pm 6,39$ & $43,26 \pm 6,21$ & 0,000 \\
\hline & Hy $-\mathrm{N}$ & $112,80 \pm 9,50$ & $115,08 \pm 10,41$ & 0,009 \\
\hline & Hy - S & $91,78 \pm 9,78$ & $96,10 \pm 11,23$ & 0,000 \\
\hline & $\mathrm{Hy}-\mathrm{SN}$ & $92,48 \pm 8,64$ & $97,20 \pm 9,82$ & 0,000 \\
\hline & Hy - MD & $12,42 \pm 5,54$ & $11,95 \pm 4,70$ & 0,300 \\
\hline & Hy - FH & $74,09 \pm 7,82$ & $76,66 \pm 9,37$ & 0,001 \\
\hline & Hy - PTV & $-1,25 \pm 6,56$ & $1,53 \pm 6,86$ & 0,000 \\
\hline & Hy - VRD & $2,14 \pm 10,27$ & $5,81 \pm 12,03$ & 0,000 \\
\hline & Hy- HRD & $94,26 \pm 8,69$ & $98,23 \pm 10,21$ & 0,000 \\
\hline
\end{tabular}

$\bar{x}:$ Ortalama; SS: Standart Sapma; P:Bağımsız grup t testi; $p>0,05$

\section{TARTIŞMA}

Günümüzde ortodontinin hızlı şekilde gelişimi ile ortodontistlerin ilgi alanları da genişlemiş, kraniyofasiyal yapılar ve komşu bölgeler de incelenmeye başlanmıştır. Hyoid kemik, dil, yumuşak damak ve havayolu ortodontistlerin araştırmalarına konu olmuş önemli bölgelerdendir. Literatürü incelediğimizde farengeal havayolu boyutlarının ve hyoid kemik pozisyonunun birçok faktörden etkilendiği görülmüştür. Çalışmalarda bu faktörlerle havayolu boyutlarının ilişkisi araştırılmıştır. ${ }^{16,17}$

Farengeal havayolu boyutları cinsiyet farklılıklarından da etkilenmektedir. Abramson ve ark. havayolu boyutlarının yaş ve cinsiyetle değişimini incelemek için yaptıkları 3 boyutlu çalışmada, kadın ve erkeklerin doğrusal, alansal ve hacimsel farengeal havayolu_ölçümlerini karşılaştırmışlar ve vertikal havayolu uzunluğu dışındaki hiçbir doğrusal, alansal ve hacimsel ölçümlerde istatistiksel olarak anlamlı bir fark bulmadıklarını belirtmişlerdir. ${ }^{18}$

Bu çalışmanın sonucunda da; erkeklerde havayolu boyutlarının ve alan ölçümlerinin kadınlara göre daha fazla olduğu görülmüştür. Bu ölçümlerden 21 ölçümün 8 'inde istatistiksel olarak anlamlı düzeyde farklılık tespit edilmiştir. Literatür incelendiğinde, genel olarak havayolu çalışmalarında obstruktif uyku apnesine sahip bireyler ${ }^{19}$ ya da farklı maloklüzyonlara sahip bireyler $^{20}$ cinsiyet açısından karşılaştırılmıştır. Bu nedenle mevcut çalışma ile direkt ilişkili literatür sayısı sınırlıdır. Çalışmanın bulguları tartışılırken benzer niteliğe sahip literatürle karşılaştırmalar yapılmıştır.

Daniel ve ark. MRG tekniği kullanarak 10 kadın ve 10 erkek toplam 20 gönüllü sağlıklı birey üzerinde yaptıkları çalışmalarında, erkeklerin kadınlara oranla daha büyük sagittal farengeal boyutlara sahip olduğunu; dil, yumuşak damak kalınlık ve uzunluğunun erkeklerde daha fazla olduğunu belirtmişlerdir. ${ }^{11}$ Çalışmamızda elde ettiğimiz bulgulara göre de erkeklerde bazı seviyelerde farengeal havayolu uzunluklarının (PFU, EHU ve AFU) kadınlara göre daha fazla olduğu ortaya konmuştur.

Farklı iskeletsel maloklüzyonların Sınıf I maloklüzyona sahip bireylerle farengeal havayolu açısından karşılaştırıldığı çalışmalarda da Sınıf III maloklüzyona sahip kadınların normal iskeletsel paterne sahip bireylerle benzer farenks hacmi gösterdiği bildirilmiştir. ${ }^{21}$ Cinsiyetler arasındaki farengeal havayolu farklılıklarının yaşa göre incelendiği farklı bir çalışmada da 10 yaş üzeri bireylerde kadın ve erkeklerde farengeal havayolu boyutlarının farklılık gösterdiği tespit edilmiştir. ${ }^{22}$

Sağlam ve Uydaş, 38 kadın ve 38 erkek toplamda 76 hasta üzerinde yaptıkları, kadınlar ve erkekler arasındaki baş postürü ve hyoid pozisyonu farklılıklarını değerlendirdikleri sefalometrik çalışmalarında, kraniyoservikal ölçümler arasında kadın ve erkeklerde anlamlı düzeyde farklılık tespit edilmediğini, hyoidin erkeklerde kadınlara göre daha aşağıda ve önde konumlandığını bildirmişlerdir. ${ }^{23}$ Mevcut çalışmanın bulguları da, bu çalışmanın sonuçları ile örtüşmektedir. Çalışmamızda da hyoid kemik erkeklerde vertikal olarak aşağıda ve önde bulunmuştur.

Hyoid kemiğin konumunun değerlendirildiği birçok araştırmada cinsiyetler arası farkın yeterli ölçüde araştırılmadığı tespit edilmiştir. Daha önceden yapılmış birçok çalışmaya her iki cinsiyetten bireyler dâhil edilmiş ancak cinsiyet ayrımı gözetilmemiştir. ${ }^{24} \mathrm{Bu}$ nedenle çalışmamıza her iki cinsiyetten bireyler dâhil edilmiş olup, cinsiyetin hyoid kemiğin konumuna olan etkisinin de değerlendirilmesi hedeflenmiştir.

Kollias ve Krogstad, 20 yıllık longitudinal sefalometrik takip çalışmalarında, erişkin bireylerdeki hyoid kemik ve kraniyoservikal bölgedeki konumsal değişiklikleri araştırmışlardır. ${ }^{25}$ Çalışmada 24 kadın ve 26 erkek bireyden, 22 ile 42 yaşlar arasındaki dönemde 10 yıl aralıklarla üç lateral sefalometrik röntgen alınmıştır. Araştırmacılar, Hy-CV3ai mesafesinin erkek ve kadınlarda benzer olduğunu, hyoid kemiğin horizontal konumunda yaş ve cinsiyete bağlı anlamlı bir fark bulunmadığını ve hyoid kemiğin erkeklerde kadınlara göre yaş ilerledikçe daha aşağıda konumlandığını bildirmişlerdir.

Ceylan, 13-15 yaşlar arasında bulunan $45 \mathrm{kIz}$ ve 45 erkek toplam 90 bireyi dâhil ettikleri ve ANB açısına göre Sınıf I, Sınıf II ve Sınıf III olarak 3 grup oluşturdukları tez çalışmasında; cinsiyetin ve ANB 
açısının doğal baş pozisyonu ve hyoid kemiğin pozisyonuna olan etkilerini incelemişlerdir. ${ }^{7}$ Hyoid kemiğin, kadınlarda erkeklere göre önemli düzeyde yukarıda ve geride konumlandığını ancak doğal baş konumu açısından cinsiyetler arasında anlamlı farklıı̆̆ın bulunmadığını belirtmişlerdir. ${ }^{7}$ Bu çalışmanın bulgularıyla paralel olarak çalışmamızda hyoid kemiğin konumunun kadınlarda erkeklere oranla daha yukarıda ve geride olduğu gözlenmiştir.

Mortazavi ve ark. iskeletsel Sınıf I, II ve III bireylerde hyoid kemiğin konumunu tespit etmek ve cinsiyet farklııklarını incelemek amacıyla çalışmalarına 110 bireyi dâhil etmişlerdir. Hyoid kemik erkeklerde kadınlara göre daha aşağıda ve önde konumlanmış olup, iskeletsel gruplar arasında ise Sınıf I bireylerde daha önde ve aşağıda, Sınıf II bireylerde ise daha geride konumlandığını rapor etmişlerdir. ${ }^{26}$

Cinsiyetler arasında kraniyofasiyal boyutlardaki farklılık, çeşitli çalışmalarda ortaya konan bir gerçektir. ${ }^{27,28}$ Genelde, kadınlar fiziksel olarak erkeklerden daha küçük boyutlara sahiptirler (daha az kas kütlesi ve daha küçük kranyum). Bu nedenle kadınların daha az oksijen gereksinimine bağlı olarak çalışmalarda, kadınlarda havayolu genişliğinin erkeklerdekine benzer boyutlarda olduğu durumlarda farengeal havayolu boyutlarının oran olarak erkeklerden daha büyük olduğu bildirilmiştir. ${ }^{29}$

\section{SONUÇ}

Kadın ve erkeklere göre farengeal havayolu boyutlarını değerlendirdiğimiz çalışmamızın sonucunda; erkeklerde havayolu boyutlarının ve alan ölçümlerinin genel olarak daha fazla olduğu görülmüştür.

Farengeal havayolu ölçümlerinin \% 38'inde cinsiyetlere göre farklılık tespit edilirken, \%62'sinde kadın ve erkekler arasında hiçbir fark bulunmamıştır.

Hyoid kemik pozisyonunda ise, erkeklerde hyoid kemiğin vertikal olarak aşağıda ve önde olduğu sonucuna ulaşılmıştır.

Tüm yazarlar yukarda ismi geçen çalışmanın daha önce bilimsel platformda yer almadığını, yayında herhangi bir çıkar çatışması olmadığını taahhüt etmektedirler

\section{KAYNAKLAR}

1. Li L, Liu H, Cheng $H$, Han $Y$, Wang $C$, Chen $Y$, Song J, Liu D. CBCT evaluation of the upper airway morpho- logical changes in growing patients of class II divi- sion 1 malocclusion with mandibular retrusion using twin block appliance: a comparative research. Plos One 2014; 9:e94378.
2. Pierce RJ, Worsnop CJ Upper airway function and dysfunction in respiration. Clin Exp Pharmacol Physiol 1999; 26:1-10.

3. Baker TL. Introduction to sleep and sleep disorders. Med Clin North Am. 1985; 69:1123-52.

4. Graber LW. Hyoid changes following orthopedic treatment of mandibular prognathism. Angle Orthod 1978; 48:33-8.

5. Bench RW. Growth of the cervical vertebrae as related to tongue, face, and denture behavior. Am J Orthod 1963; 49:183-214.

6. Gustavsson U. Hyoid bone position in relation to head posture. Swed Dent J 1972; 65:423-30.

7. Ceylan İ. Değişik ANB açılarında doğal baş konumunu ve hyoid kemiğinin konumunun incelenmesi Atatürk Üniversitesi Sağlık Bilimleri Enstitüsü, Doktora Tezi, Erzurum, 1990.

8. Dinçer B, Erdinc A, Önçağ G, Doğan S. Sınıf I, Sınıf II D I, Sınıf III anomalilerde hyoid kemiginin konumunun incelenmesi. Türk Ortodonti Derg 2000; 13:108-15.

9. Günaydın Ç. Nazo-oro-farengeal hava yolu boyutlarının farklı maloklüzyonlarda gelişiminin longitudinal olarak incelenmesi. Ankara Üniversitesi Sağlık Bilimleri Enstitüsü, Doktora Tezi, Ankara, 2015.

10. Aboudara C, Nielsen I, Huang JC, Maki K, Miller AJ, Hatcher D. Comparison of airway space with conventional lateral head films and 3-dimensional reconstruction from cone-beam computed tomography. Am J Orthod Dentofacial Orthop 2009; 135:468-79.

11. Daniel MM, Lorenzi MC, Leite CdC, Lorenzi-Filho G. Pharyngeal dimensions in healthy men and women. Clinics. 2007; 62:5-10.

12. Kim YJ, Hong JS, Hwang YI, Park YH. Threedimensional analysis of pharyngeal airway in preadolescent children with different anteroposterior skeletal patterns. Am J Orthod Dentofac Orthop 2010; 137:306.e1-e11.

13. Tourne L. Growth of the pharynx and its physiologic implications. Am J Dentofacial Orthop 1991; 99:129-39.

14. Tourne $L$. The long face syndrome and impairment of the nasopharyngeal airway. Angle Orthod 1990; 60:167-76.

15. Lowe AA, Fleetham JA, Adachi S, Ryan CF. Cephalometric and computed tomographic predictors of obstructive sleep apnea severity. Am J Orthod Dentofacial Orthop 1995; 107:589-95. 
16. Tarkar JS, Parashar S, Gupta G, Bhardwaj P, Maurya RK, Singh A, Singh P. An evaluation of upper and lower pharyngeal airway width, tongue posture and hyoid bone position in subjects with different growth patterns. J Clin Diagn Res 2016; 10:ZC79-83.

17. Nejaim Y, Aps JK, Groppo FC, Neto FH. Evaluation of pharyngeal space and its correlation with mandible and hyoid bone in patients with different skeletal classes and facial types. Am J Orthod Dentofacial Orthop 2018; 153:825-33.

18. Abramson Z, Susarla S, Troulis M, Kaban L. Agerelated changes of the upper airway assessed by 3-dimensional computed tomography. J Craniofac Surg 2009; 20:657-63.

19. Inoshita A, Kasai T, Matsuoka R, Sata N, Shiroshita N, Kawana F, Kato M, Ikeda K. Age-stratified sex differences in polysomnographic findings and pharyngeal morphology among children with obstructive sleep apnea. J Thorac Dis 2018; 10:, 6702-10.

20. Nath M, Ahmed J, Ongole R, Denny C, Shenoy N. $\mathrm{CBCT}$ analysis of pharyngeal airway volume and comparison of airway volume among patients with skeletal Class I, Class II, and Class III malocclusion: A retrospective study. Cranio 2019; 12:1-12.

21. Bozzini MFR, Valladares-Neto J, Paiva JBD, RinoNeto J Sex differences in pharyngeal airway morphology in adults with skeletal Class III malocclusion. Cranio 2018; 36:98-105.

22. Jiang $Y Y, X u X, S u H L$, Liu DX. Gender-related difference in the upper airway dimensions and hyoid bone position in Chinese Han children and adolescents aged 6-18 years using cone beam computed tomography. Acta Odontol Scand 2015; 73:391-400.

23. Sağlam AMŞ, Şenışık NE. Upper airway morphology and head posture in healthy men and women. SDÜ Sağ Bil Derg 2017; 8:12-17.

24. Durzo CA, Brodie AG. Growth behavior of the hyoid bone. Angle Orthod 1962; 32:193-204.

25. Kollias I, Krogstad O. Adult craniocervical and pharyngeal changes-a longitudinal cephalometric study between 22 and 42 years of age. Part 1 : morphological craniocervical and hyoid bone changes. Eur J Orthod 1999; 21:333-44.
26. Mortazavi S, Asghari-Moghaddam H, Dehghani M, Aboutorabzade M, Yaloodbardan B, Tohidi E, Hoseini-Zarch $\mathrm{SH}$. Hyoid bone position in different facial skeletal patterns. J Clin Exp Dent 2018; 10:e346-e351.

27. Schudy FF. The rotation of the mandible resulting from growth: its implications in orthodontic treatment. Angle Orthod 1965; 35:36-50.

28. Bishara SE, Ortho D, Jakobsen JR. Longitudinal changes in three normal facial types. Am J Orthod 1985; 88:466-502.

29. Mislik B, Hänggi MP, Signorelli L, Peltomäki TA, Patcas R. Pharyngeal airway dimensions: a cephalometric, growth-study-based analysis of physiological variations in children aged 6-17. Eur J Orthod 2013; 36:331-9.

\section{Sorumlu Yazarın Yazışma Adresi}

Dr. Öğr. Üyesi Muhammed Hilmi BÜYÜKÇAVUŞ

Süleyman Demirel Üniversitesi

Diş Hekimliği Fakültesi

Ortodonti AD

Isparta / TÜRKİYE

05065073846

muhammedbuyukcavus@sdu.edu.tr

mhbuyukcvs@gmail.com 